University of South Florida

DIGITAL COMMONS

Digital Commons @ University of

@ UNIVERSITY OF SOUTH FLORIDA

South Florida

$11-5-2015$

\title{
Response to Bullying (RtB): Behavioral Skills and In Situ Training for Individuals Diagnosed with Intellectual Disabilities
}

\author{
Rebecca Lynn Stannis \\ University of South Florida, rstannis@mail.usf.edu
}

Follow this and additional works at: https://digitalcommons.usf.edu/etd

Part of the Social and Behavioral Sciences Commons

\section{Scholar Commons Citation}

Stannis, Rebecca Lynn, "Response to Bullying (RtB): Behavioral Skills and In Situ Training for Individuals Diagnosed with Intellectual Disabilities" (2015). USF Tampa Graduate Theses and Dissertations.

https://digitalcommons.usf.edu/etd/6028

This Thesis is brought to you for free and open access by the USF Graduate Theses and Dissertations at Digital Commons @ University of South Florida. It has been accepted for inclusion in USF Tampa Graduate Theses and Dissertations by an authorized administrator of Digital Commons @ University of South Florida. For more information, please contact digitalcommons@usf.edu. 
Response to Bullying (RtB): Behavioral Skills and In Situ Training for Individuals Diagnosed with Intellectual Disabilities

by

\title{
Rebecca Lynn Stannis
}

\author{
A thesis submitted in partial fulfillment \\ of the requirements for the degree of \\ Master of Arts \\ Department of Child and Family Studies \\ College of Behavioral and Community Science \\ University of South Florida
}

\section{Co-Major Professor: Kimberly Crosland, Ph.D., BCBA-D Co-Major Professor: Raymond Miltenberger, Ph.D., BCBA-D Kimberly Church, Psy.D., BCBA-D}

Date of Approval:

October 29, 2015

Keywords: safety skill, walk away, tell staff, comment of disapproval, adult, group home Copyright (C) 2015, Rebecca Lynn Stannis 


\section{Dedication}

I'd like to dedicate this thesis to my parents, Dawn and Gary, for encouraging me to pursue everything I want in life and always give 100\%. Thank you for your support, unconditional love, and for constantly shaping me into the person I am today, allowing me to achieve things I never once thought possible. 


\section{Acknowledgments}

It is an honor to have the opportunity to thank those that have greatly assisted and supported me throughout the completion of this thesis as well as my entire graduate school experience. First, I'd like to thank my advisors and committee members, Dr. Crosland, Dr. Miltenberger, and Dr. Church, for their support, expertise, and guidance throughout this project. Thank you to Stephani Fauerbach, the behavior team, and everyone at the Human Development Center for their support and assistance through this project, for teaching me many valuable skills, and introducing me to the many different ways ABA can be applied. Thank you to my many research assistants who assisted with IOA and were very flexible throughout this process, specifically thank you to Katelin Russ for you assistance during training sessions and assessments. Thank you to Diego Valbuena for your countless hours of assistance from the initial project proposal to training sessions, manuscript recommendations, and overall contributions to this project. Thank you to my family, friends, and all my cohort members for their support and encouragement throughout this long, sometimes crazy process. I'd like to thank my confederates and participants for making this thesis possible; I could not have done this without you. And last but not least, I'd like to thank all my professors at the USF ABA Masters program and my professors from my undergrad at FSU who shaped me into the behavior analyst I am today and encouraged me to pursue a field that I absolutely love. 
Table of Contents

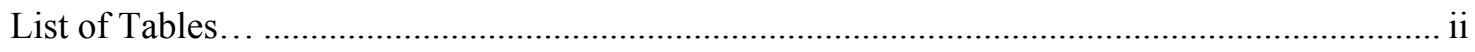

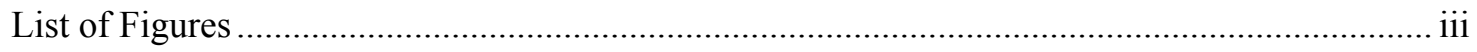

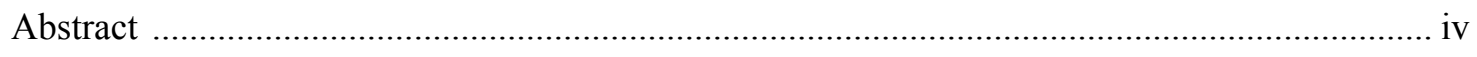

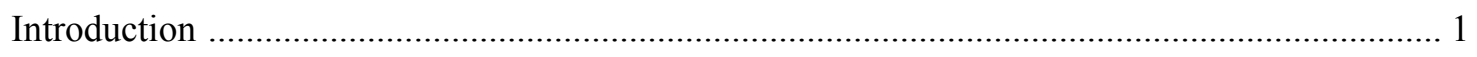

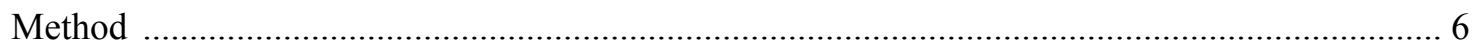

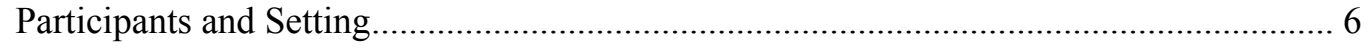

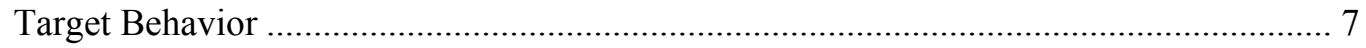

Training and Treatment Fidelity of Confederates......................................................... 8

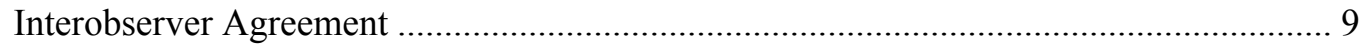

Design and Procedures.......................................................................................... 9

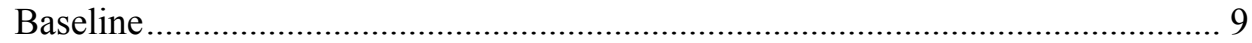

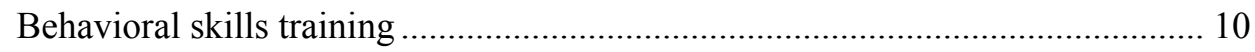

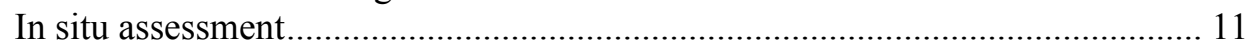

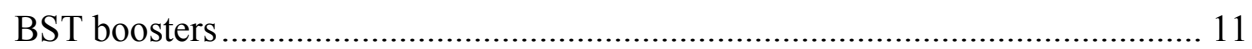

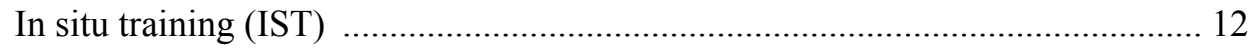

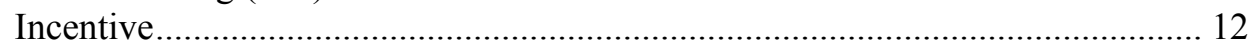

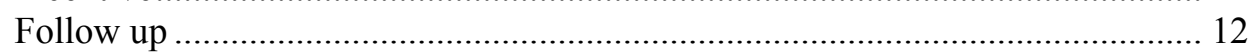

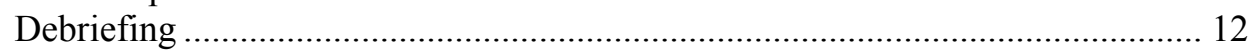

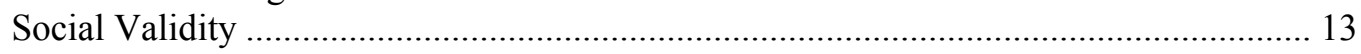

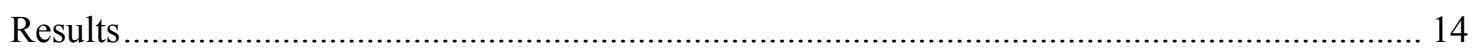

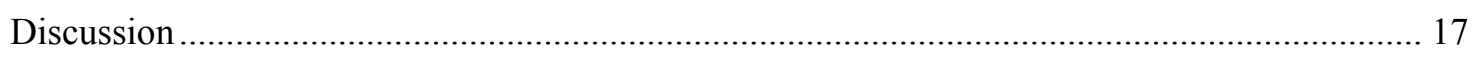

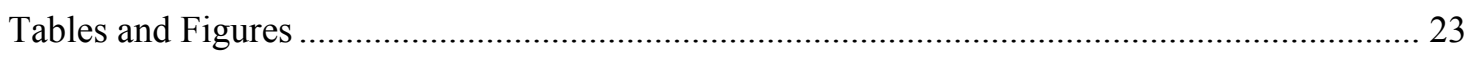

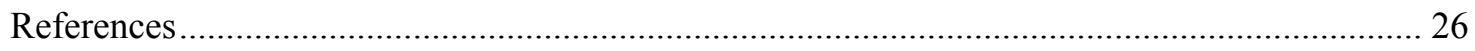

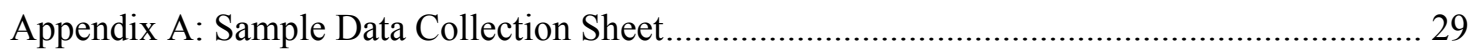

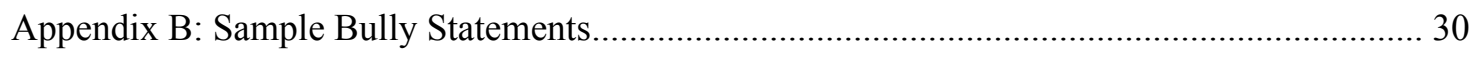

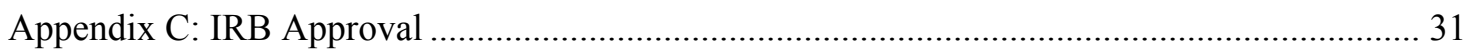




\section{List of Tables}

Table 1: The responses of participants and confederates on the social validity

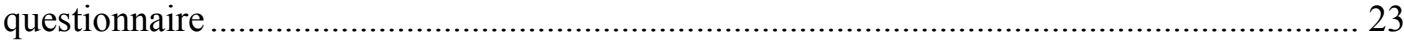

Table 2: The responses of staff on the social validity questionnaire 


\section{List of Figures}

Figure 1: Rating-scale scores for participants across baseline, BST, IST, and incentive Phases. 


\begin{abstract}
Bullying is a continuing problem for adults with intellectual disabilities who live in group homes and attend adult day training settings together. Many different intervention approaches have been reviewed. Most research in this area focuses on bullying in schools with typically developing children, and therefore, a need for effective behavioral interventions for adults with intellectual disabilities still remains. Previous research has found success in teaching safety skills to a variety of populations using behavioral skills training (BST) and achieving generalization of these skills using in situ training (IST). This study evaluated BST to teach a response to bullying (RtB) to the victims of bullying, with added IST for participants whose skills did not generalize to the natural environment. This study attempted to remove the hypothesized reinforcer of social attention from the perpetrator of bullying. In situ assessments (ISA) were conducted in the natural setting after BST sessions had already occurred. When BST was not sufficient in evoking the correct response during ISA, IST was added for 2 participants and an incentive was added for 1 participant to increase motivation when responding still did not meet completion criteria. However, BST alone was successful in teaching the RtB to two participants, evident by their responses during ISA. The results of this study are consistent with previous BST and IST research.
\end{abstract}




\section{Introduction}

Bullying is a serious problem that necessitates effective interventions. Victims of bullying may be at an increased risk for depression, anxiety, sleep difficulties, and poor school adjustment (Center for Disease Control, 2012). Victims of bullying often report low self-esteem or damage to self-concept, which often leads to engagement in behaviors such as aggression (Fried \& Fried, 1996). Many times bully victims are hurt physically as well, reports of students in comas and under temporary paralysis after bully incidents are some examples of the severe physical harm that can result from bullying (Fried \& Fried, 1996). Bullying can also lead to death of the victim or the bully; for this reason, bullying should not be considered a minor problem and should never be ignored (Fried \& Fried, 1996).

Bullying may be an even bigger problem with individuals who have intellectual disabilities. For example, Reiter and Lapidot-Lefler (2007) found that $83 \%$ of students in two special education schools reported experiencing some type of bullying. Research has found that individuals with intellectual disabilities who bully may also engage in other challenging behaviors such as stealing, lying, and throwing temper tantrums (Reiter \& Lapidot-Lefler, 2007). McGrath, Jones, and Hastings (2010) found that 43\% of adults with intellectual disabilities reported they had been bullied within the preceding three months. Surveys conducted by Mencap (1999) reported that nearly nine out of 10 individuals with learning disabilities had been bullied in the last year and two-thirds reported being bullied on a regular basis. While some research has found a lower percentage of acts of bullying reported by individuals with intellectual disabilities (25\%), when these acts did occur, they were perceived as high intensity and stressful (Bramston, 
Fogarty, \& Cummins, 1998). The high intensity and frequency of these behaviors can cause damaging effects on individuals, including physical harm and social isolation (Fried \& Fried, 1996). Because of these damaging effects, effective behavior analytic interventions are needed to teach victims a way to respond to bullying that does not provide reinforcement for the bully.

There is inconsistency in the definition of bullying in the literature, but some definitions contain similar elements. For example, some researchers state that bullying must include intent to harm, abuse of and unbalance of power (Garrity, Jens, Porter, Sager, \& Short-Camilli, 1997), physical size and social status differences (Craig, Pepler, \& Blais, 2007), victims targeted repeatedly over the course of time (Garrity et al., 1997), and actual physical or mental harm perceived by the victim (Colvin, Tobin, Beard, Hagan, \& Sprague, 1998). A limitation of the definitions listed above is that they do not allow for accurate measurement because many of the terms used can only be measured subjectively. In order to control for the subjectivity in the definition of bullying, operational definitions of bullying behavior may consist of two subsets: physical aggression and verbal aggression. Physical aggression might consist of such behaviors as hitting, kicking, choking, grabbing, flicking and punching. Verbal aggression might consist of such behaviors as teasing, threatening, vulgar language towards another, vulgar gestures towards another, rude comments about ones appearance, and slang and inappropriate name-calling. For the purpose of this study, these definitions will be used along with the addition of individual topographies of bully behavior reported to be perceived by participants.

Most bullying studies have been conducted with typically developing children and have taken place in the school system, these interventions are typically not individualized (Ross \& Horner, 2009; Yang \& Salmivalli, 2015). Many interventions in the literature also use self-report measures to express a decrease in self-reported bullying for either the bully or victim 
(Christensen, Fraynt, Neece,, \& Baker, 2012; McGrath et al., 2010). It is possible the selfreports used may be indicative of a perception of less bullying rather than an overall decrease in bullying behavior due to the subjectivity of self-report measures. It is most desirable to use direct observation methods for taking data immediately when behaviors occur because data taken at later times can be skewed and recorded incorrectly (Miltenberger, 2008).

Little behavior analytic research has focused on bullying behavior or the behavior of the victims of bullying. However, some success has been found in implementing school-wide bullying programs that are behavior analytic in nature, such as school wide positive behavior support (Ross \& Horner, 2009). Ross and Horner (2009) implemented School Wide Bully Prevention in Positive Behavior Support (BP-PBS), an intervention where children were taught to withhold social rewards thought to maintain bullying behavior. BP-PBS was designed to teach "being respectful" by encouraging all students to use a three-step response (stop, walk, talk). The results show an overall steady decrease in the frequency of incidents of bullying for each of the six target students after intervention was implemented (Ross \& Horner, 2009). Some limitations of this study were the hypothesized the function of the behavior to be attention without the use of a functional analysis and the lack of individualized procedures. The authors of this study suggest that individualized interventions may help achieve stronger reduction levels in aggressive behaviors. This study, however, supports the hypothesis that bully victims can be taught to minimize attention by engaging in the three-step response or RtB and shows a decrease in bullying when the responses were used (Ross \& Horner, 2009).

Behavioral skills training is an intervention that has been used to successfully teach various safety skills to many different populations (Gatheridge et al., 2004; Himle, Miltenberger, Flessner, \& Gatheridge, 2004; Miltenberger, Roberts, Ellingson, \& Galensky, 1999; 
Miltenberger et al., 2004; Miltenberger et al., 2005; Sanchez \& Miltenberger, 2015). Behavioral skills training uses four components: instruction, modeling, rehearsal, and feedback. Travis and Sturmey (2013) used behavioral skills training to teach replacement responses for aggression and decreased aggressive responses in individuals with intellectual disabilities. Because of the successful results in the studies by Travis and Sturmey (2013) and Ross and Horner (2009), it was hypothesized that BST might be an effective strategy to decrease bullying behavior and increase safety responses in adults with intellectual disabilities. Although behavior skills training (BST) is typically successful at teaching skills for acquisition, participants often do not show generalization of these skills to natural settings. Researchers have found that adding in situ training (IST) improves generalization of these skills for some participants (Himle et al., 2004; Miltenberger et al., 1999; Miltenberger et al., 2005).

IST is implemented immediately after the participant fails to perform the safety skills in ISA, each failed assessment is an opportunity to teach the participant the correct responses by implementing corrective feedback and rehearsal of the correct behavior (Egemo-Helm et al., 2007; Himle et al., 2004; Miltenberger et al., 1999; Miltenberger et al., 2005; Sanchez \& Miltenberger 2015). IST has been used to increase generalization after the use of BST (Himle et al., 2004; Miltenberger et al., 1999). Miltenberger et al. (2004) used IST, when necessary, to increase the participants use of the safety skills when encountering firearms. This study showed that when a participant did not show the safety skills after receiving BST, IST was implemented, and the participants demonstrated the desired gun safety skills consistently after one to four IST sessions. The results of the study by Himle et al. (2004) show that nearly half of the children required IST. Miltenberger et al. (1999) used IST to increase sexual abuse prevention skills in women with mental retardation following 10 BST sessions, all women required IST. Sanchez 
and Miltenberger (2015) used IST to increase abduction prevention skills in young adults with intellectual disabilities when the skills taught in BST did not generalize to the natural environment. IST was effective in achieving the criterion level for half of the participants. Half of the participants achieved 3 out of 4 abduction prevention steps correct following IST, due to not telling an adult about the interaction.

While some research has been published concerning bullying behavior in children at schools, very little research has focused on adults with intellectual disabilities who bully each other. Self-reports show that $43 \%$ of adults with intellectual disabilities reported they had been bullied in the preceding 3 months and $28 \%$ of adults with intellectual disabilities reported that they bullied others in the preceding three months. (McGrath et al., 2010). Although there is little research published, the author's own observations show high frequencies of aggressive and bullying behaviors of adults with intellectual disabilities. There are two main purposes of this study. The first purpose is to evaluate a BST program that teaches adults with intellectual disabilities a response to bullying (RtB). The second purpose of this study is to evaluate IST to teach the response to bullying (RtB) if skills taught in BST do not generalize to the natural environment. 


\section{Participants and Setting}

\section{Method}

Four men with intellectual disabilities participated in this study. Sheldon, 42 years old, was diagnosed with mild intellectual disability and impulse control disorder with psychotic features. Leonard, 64 years old, was diagnosed with severe intellectual disability. Raj, 48 years old, was diagnosed with mild intellectual disability and anxiety. Howard, 34 years old, was diagnosed with mild intellectual disability and behavioral issues.

All participants resided at community-based Intensive Behavioral Residential Habilitation group homes and received behavior services to reduce problem behavior and increase daily living skills at the time of the study. An Intensive Behavioral Residential Habilitation group home promotes the independence of individuals who display high risk behavior by providing support and training designed to reduce or replace severe challenging behavior. The adults selected for inclusion in this study were chosen based on clinical and direct care staff referrals. Participants who staff reported were currently experiencing bullying by peers and were residents at the agency in one of the group homes for at least 6 months, were included in this study. Inclusion criteria for participants also required that participants did not have a history of physical aggression within the past 3 months.

Confederate participants were recruited to conduct in situ assessments (ISA). These participants consisted of three men with mild intellectual disabilities who lived in the supported living setting (their own apartment with supported living coaches and behavior analysis supports). Inclusion of all confederate participants required that they were currently in contact with participants, they stated that they understood this is only a training role-play, and that they 
agreed to consent forms regarding the debriefing and training session following the intervention.

ISA and IST took place at the residential group home setting and at the Adult Day Training (ADT) center. Individuals who resided at these group homes attended ADT centers during the day to learn life and work skills. Three levels of supervision and support were available at the residential facility. The main campus consisted of two group homes that gave 24hr supervision to 12 individuals, and the ADT facility was located on this campus as well. The next level of support and supervision was at the community-based group homes where residents moved once they demonstrated a steady decrease in problem behaviors and increases in replacement behaviors but still required 24-hr supervision. Once individuals showed an increase in independent living skills and the ability to manage their own behavior effectively, they moved out of the residential group homes into supported living where they still received 24-hr support without constant supervision.

\section{Target Behavior}

The RtB consisted of four safety skills that were targeted in this intervention. These skills included: 1) refrain from retaliating against the bully by avoiding physical contact or verbal statements other than those taught in BST, 2) state only a short comment of disapproval, such as "I don't like that," 3) walk away from the bully, and 4) tell a staff member about the interaction. Direct observation data were collected on all four components of the 5-point response (See Appendix A). These data were presented as steps correct per assessment. The target behavior exhibited after the bully statement was scored using a 5-point scale. A score of 0 was given if the participant retaliated against the bully confederate verbally or physically, regardless of his engagement of any of the other three steps. A score of 1 was given if the participant did not retaliate against the bully confederate, but did not engage in any of the other three steps. A score 
of 2 was given if the participant did not retaliate against the bully and engaged in one of the following steps: walked away within $5 \mathrm{~s}$ of the bully interaction, stated the statement of disapproval, or told a staff member. A score of 3 was given if the participant did not retaliate against the bully, and engaged in two of the following steps: walked away within $5 \mathrm{~s}$ of the bully interaction, stated the statement of disapproval, or told a staff member about the interaction. A score of 4 was given if the participant refrained from retaliating against the bully, walked away within $5 \mathrm{~s}$ of the bully interaction, stated the statement of disapproval, and told a staff member about the interaction.

\section{Training and Treatment Fidelity of Confederates}

Confederates participated in BST on how to complete the ISA and state the bully statement to participants. Training was conducted using BST components: instructions, modeling, rehearsal, and feedback to ensure accurate implementation of the bully statement. During training, the confederate was required to demonstrate the use of the four steps of the bullying statement by role-playing the bully scenario with the researcher. The four steps of the bully scenario included: 1) walk up to within $1.6 \mathrm{~m}$. of the participant, 2) say the short bully statement, 3) walk away from the participant within $5 \mathrm{~s}$, and 4) do not do or say anything else besides the bully statement to the participant. The confederate was required to demonstrate $100 \%$ use of the four steps in three consecutive role-plays with the researcher prior to ISA.

Treatment integrity data were taken during $100 \%$ of all assessments (See Appendix A). The researcher observed the confederate's behavior and took data on each component of the bully role-play. Treatment integrity scores were $99 \%$ across all confederates. One confederate did score $50 \%$ during one assessment, due to speaking back to the participant when asked about an unrelated topic and not walking away in the $5 \mathrm{~s}$ time frame. He was re-trained immediately 
prior to any further assessments.

\section{Interobserver Agreement}

Two observers independently, but simultaneously, scored all responses on the target behavior data collection sheets. This was completed during all phases of the study for a total of $41 \%$ of all assessments. IOA was calculated by dividing the number of agreements on the four target behaviors by the number of agreements plus disagreements then multiplying by 100 for a percentage. IOA was determined to be $95 \%$ for Sheldon, $100 \%$ for Leonard, $95.8 \%$ for Raj, and $100 \%$ for Howard.

\section{Design and Procedures}

A multiple baseline across participants design was used to demonstrate a functional relationship between BST and IST (when necessary) and the use of the RtB by bully victims. All of the participants had a behavior analysis services plan (BASP) in place that remained the same throughout all phases of the study. A staff member was always within $1.6 \mathrm{~m}$ of the participants during assessments to intervene if necessary to ensure the safety of all participants and bystanders.

Baseline. ISA took place in the natural setting at the residential group home and ADT facilities. Staff were instructed to respond as they typically would with the participant's current BASP and were always present in the room, as required by the agency to ensure safety. Confederates conducted each ISA that consisted of stating a short bully statement to the participant and walking away from the area after $5 \mathrm{~s}$ regardless of the participant's response. Bully statements were determined based on discussions with clinical and direct care staff at the group homes as to the types of bullying comments that clients at the group homes were likely to say to each other and later the participants were questioned on the bully statements (See 
Appendix B) to ensure the participants perceived these comments as bullying. Bully statements were categorized into four different types: threats of personal harm, threats of loss of privileges/property, personal defamations/name calling, and obscenities (including swearing or rude gestures). Bully statements were chosen at random prior to each ISA and different types of statements were presented across phases. During baseline, the confederate entered the room, walked up to the participant and stated a bully statement such as "I'm going to rip your head off," then walked away within 5 s. Direct observation data was collected on the participants' response to the bully statement from the confederate.

Behavioral skills training. Two 30-min behavioral skills training sessions were conducted for each participant. These sessions took place in a classroom at the ADT setting, with the exception of Sheldon, whose sessions took place at an office after he got off work. A training information session was conducted which consisted of informing each participant of the bullying definition, what behaviors bullying consisted of, and questioning the participants on bully situations that occurred to them recently to assure the participants understood what behaviors to respond to when they encountered these situations and that the statements from the confederates were actually perceived as bullying by the participants.

Instructions consisted of the researcher telling the participants how to respond to bullying by using the RtB. The first step was that the participant refrain from retaliating in any way to the bully (do not cry, whine, hit, laugh, or engage in verbal aggression). The second step in the RtB was to say a short statement of disapproval chosen by the participants, such as, “I don't like that." The third step was to walk away from the area. The fourth step was to tell a staff member about the incident, and the staff member was to provide praise.

Modeling consisted of the researcher and research assistants modeling this RtB in a role- 
play when a bully statement was presented. Role-plays consisted of three to five role-play situations where the researcher and research assistants acted as the bully and the participants demonstrated the RtB. Each participant was required to display all four steps of the RtB three consecutive times at minimum before moving on to the post-training assessment phase.

Feedback consisted of the researcher and research assistants giving praise on every attempt and corrective feedback when necessary for incorrect responses.

In situ assessment. After each participant displayed the RtB $100 \%$ correctly during the two BST sessions, ISA were conducted in the same way as was described in the baseline phase to assess generalization of the skills taught. Once the participant correctly demonstrated the response on two or more occasions in ISA, the intervention was complete, as generalization was demonstrated.

BST boosters. If the participant did not demonstrate all the skills in the safety response during the first ISA, a booster training session was provided. If the participant still did not demonstrate all four steps of the RtB in the ISA following the first booster, a second booster was provided. During these sessions, the skills from the initial BST sessions were reviewed and practiced. The participant was required to execute the skills with $100 \%$ accuracy across three different scenarios to complete the BST booster training. Additional ISA (identical to those in the post-assessment) were then conducted to determine if the booster training was effective to increase correct responding.

In situ training (IST). Participants who still did not perform the RtB at $100 \%$ accuracy after the booster trainings received IST. This training booster consisted of the same training that took place in BST sessions conducted in-vivo. If the participant did not demonstrate the RtB during ISA, the trainer immediately intervened to conduct a training session. The trainer first 
pointed out that the participant did not use the RtB; the trainer then modeled the correct response, instructed the participant to rehearse the correct response, and then gave praise and corrective feedback when needed. The participant was required to rehearse the correct response twice.

Incentive. Due to Leonard's low scores across all phases, an incentive was added in an attempt to increase his motivation to use the RtB. During this phase, the researcher met with Leonard and explained to him that he would earn an item of his choosing (from an array of items identified by staff as putative reinforcers for Leonard) if he engaged in the correct response. Leonard was then given the opportunity to role-play the RtB with the researcher and after three consecutive trials completed at $100 \%$ accuracy, he received one of the items.

Follow up. The maintenance of the RtB was assessed 3 weeks after the last phase for three of the participants. Follow up assessments were conducted in an identical fashion to the ISA throughout all phases of the study where bully confederates approached the participants, stated the bully statement, and data was recorded on the participant's response.

Debriefing. Following completion of intervention, each participant met with the researcher to be debriefed. The researcher explained the nature and reasons for deception, informed the participants that these individuals were acting as confederates, and explained why this was necessary. Participants and confederates were encouraged to ask any questions that they had during debriefing and to see the clinical director if they were upset and wished to discuss any concerns. The confederate was then re-introduced to the participant by the researcher. The confederate apologized, explained that it was part of the study and he was just pretending to be mean and thanked the participant for being a "good sport." Following debriefing, all of the participants reported that they understood that the confederate was "just pretending" or "didn't 
mean it." Sheldon stated that he knew we were testing him, once told that the confederate was just pretending. There were no signs that the other three participants previously knew that the confederate was "pretending."

\section{Social Validity}

Social validity questionnaires were collected for all participants, bully confederates, and staff (See Table $1 \& 2$ ). The participant and bully confederate social validity questionnaire consisted of questions regarding the likability of the procedure, whether the participants would continue using the bullying response, and if they have used the response at other times since the training. The results of the questionnaire are presented in Table 1.

The staff social validity questionnaire asked questions specific to effectiveness of the procedure and if they would recommend it for other individuals. The results are presented in Table 2. 


\section{Results}

Figure 1 shows the steps correct for all participants across baseline, BST, IST, and incentive phases. All participants scored either consecutive 0 or 1 in baseline with the exception of Howard whose data are variable, scoring between 0-2 during baseline. Three of the four participants showed an increase in steps correct following the initial BST session. Two participants received a score of 4 during two consecutive assessments following BST and two BST boosters. Two participants required IST, and one participant required an incentive phase in order to achieve a steady increase in trend for steps correct. Follow up assessments were conducted for three of the four participants 3 weeks following the last ISA for each participant. All three participants showed maintenance of the skills taught during follow up assessments.

Sheldon's exhibited one step of the RtB during baseline sessions. Sheldon did not retaliate towards the bully confederate verbally or physically during any baseline assessments. During intervention, Sheldon displayed a steady increase in responding to the first confederate; however, Sheldon's number of steps correct slightly decreased during assessments where the second confederate presented the bully statement. Sheldon's engagement in all four steps of the RtB maintained at the 3-week follow up assessment.

Leonard did not engage in any of the four steps of the RtB during baseline assessments. Leonard verbally retaliated towards the bully confederate by yelling at him specifically about the

bully statement on every occurrence. Leonard showed an immediate increase to two steps correct during the first assessment following BST, which then dropped back down and remained variable during BST and following the booster sessions. IST was implemented for Leonard and 
during this phase his scores dropped down to baseline levels. It should be noted that following feedback given by the researcher during BST boosters and IST phases, Leonard responded by yelling that he already did the steps correct and by rambling about other clients that lived in the home and how they are mean to him. Leonard's sessions often took longer to complete due to these delays and problems staying on task with the training. An incentive phase was added for Leonard to increase motivation. Leonard's number of steps correct increased to two during four consecutive assessments. However, Leonard never received the incentive during this phase due to responding still below the criterion set. Leonard was still becoming upset during this phase and reported that he did not want to engage in this response because he felt that no one was bothering him.

Raj consistently engaged in one of the four steps of the RtB during baseline assessments by not retaliating towards the bully confederate. Raj displayed a slight increase in steps correct when responding to the bully confederate after both BST sessions and both boosters. IST was implemented for Raj and an improvement to three steps can be seen on session 11. Raj reported to the researcher that he did not want to tell staff because a staff member was right there watching during each assessment. The researchers agreed that this step was not necessary during incidents where a staff was present and observing the entire incident. This last step of telling a staff member was removed from Raj's completion criteria. Raj's training was complete once he engaged in the other three steps of the RtB and his engagement in the skills maintained at the 3week follow up.

Howard's baseline data ranged from 0-2 steps correct. Howard initially retaliated verbally towards the confederate during the first three sessions. When the second confederate presented the bully statement Howard did not retaliate, and on the fifth data point, Howard was already 
walking when the bully statement was presented and he continued to walk away from the confederate without retaliating, scoring a two. After the fifth data point, Howard consistently did not retaliate towards the first confederate and unfortunately the second confederate was not available for any further assessments. Howard's scores immediately increased to four following the first BST session. Unfortunately, there was one week time lapse in data collection and on the 10th session Howard scored a one, near baseline levels. Two booster sessions were provided, after the second booster Howard scored the two consecutive assessments at four and met completion criteria with BST alone. Howard's skills maintained at the 3-week follow up. 


\section{Discussion}

Bullying can be a serious problem for adults with intellectual disabilities, especially those who live in group homes and attend ADT settings together where they are in contact with other residents $24 \mathrm{hr}$ a day. The present study evaluated a program to teach victims of bullying a way to respond to an instance of bullying, similar to that in Ross and Horner (2009). Although this intervention focused on teaching the victims a RtB, and did not directly target the perpetrators of bullying, if the perpetrators do not receive reinforcement for that behavior then the bullying behavior might decrease. In a setting such as this, where all residents come into contact with the same perpetrators of bullying on a day-to-day basis, potentially, if all residents were taught to consistently respond to bullying incidents in a way that withholds the reinforcement, then bullying at this site might decrease. Decreasing bullying at a 24-hr facility could potentially show improvements in the quality of life for these individuals. Future research could evaluate this intervention with all individuals at these types of settings.

The study extended the literature on BST and IST to a skill that had not been trained with this population. Similar to other BST and IST research (e.g., Himle et al. 2004; Miltenberger et al. 2004), not all of the participants demonstrated the skills in ISA following BST alone. In the present study, two out of the four participants (Sheldon and Howard) demonstrated all four steps of the RtB during ISA. Raj required the addition of IST to achieve three steps correct, and Leonard required IST plus an incentive to achieve two steps correct. All participants displayed an increase in steps correct during ISA following one or more phases of this intervention. The data suggest that BST may be an effective training approach to teach the RtB, however, in order 
to achieve generalization of the skills taught, some participants may require further trainings in vivo, such as IST.

During IST, the criteria were modified for Raj after he stated that he did not want to tell staff because staff were in the room and saw what happened and did not respond to the incident. The last step was taken off his completion criteria, making the RtB have 3 steps, which he scored in four consecutive assessments, and at follow-up. These results are consistent with the results of Sanchez \& Miltenberger (2015) who found that, only half of the participants told an adult about the incident but completed all other safety skills. Future research should assess the importance of this step and conduct a component analysis to determine which steps are necessary to decrease bullying and which steps keep the participants safe. For some settings and populations this step may not be necessary, especially in this example where staff were present for each ISA. Other settings may choose to include this step such as telling teachers in school settings or telling parents when working with small children. However, when including this step, the environment should be arranged so that the adult who is to be told about the bully interaction is not in view of participants during the bully interaction. For adults, this step may be more stigmatizing than it is necessary if telling the adult occurs in view of peers. The adult who is to be told about the bully interaction should also ensure that they are positioned away from peers in the environment for the privacy of the participant. More serious topographies of bully may also warrant the necessity of this step, such as physical bullying or threats of harm. The main purpose of this step was not to discipline the bully, as this would give more attention to the bully, rather the purpose was to help the individual who was bullied to deal effectively with the bully statement or threat.

Throughout the course of the study, we encountered some difficulties with Leonard. The BST sessions conducted with Leonard often took more than $30 \mathrm{~min}$, due to distractions and 
difficulty with the role-plays. Leonard engaged in a lot of rambling and attempted to engage the researchers in unrelated conversations instead of focusing on the training. An issue during roleplay trainings was that he did not want to respond to the researchers as if they were the bully perpetrators, despite them saying the bully statements that Leonard himself reported to be mean things that other residents had said to him in the past few months. Leonard stated several times during role-plays that the researchers were "not mean" and "nice ladies." A male research assistant was recruited for the following training sessions, to which Leonard still responded that this was a "nice man" and listed off many "mean men" that lived in the house with him or attended ADT with him. Despite these issues, Leonard often asked the researcher when the next training would be and reported that he enjoyed the trainings throughout the study and at the debriefing session. Another difficulty was that Leonard appeared to be frustrated on some occasions when he was given corrective feedback and would state that he already did the skills he was asked to demonstrate. The incentive phase was added in an attempt to increase motivation, but Leonard scored 2 on four consecutive trials during this phase and never earned the incentive because he did not walk away or tell staff. Leonard's participation ended at this point. At the debriefing session, Leonard stated that the confederate was not mean to him. Leonard was diagnosed with severe intellectual disability, whereas the other three participants were diagnosed with mild intellectual disability, which may have affected his acquisition of the skill.

The confederates for this study needed to perform a short bully script, leave the area after the $5 \mathrm{~s}$ (signaled by the researcher), and refrain from responding to the participants in any other way regardless of how the participants might have responded to the bully statement. Because of this, the clinical director at the study site recommended only those that she felt would be able to 
complete the ISA without responding to anything the participants may have said to them or getting upset over the interaction. These requirements greatly reduced the number of available confederates. The confederates who volunteered had previously lived with these participants but had since moved out into supported living settings where they live on their own. Supported living is the goal at this facility, so these individuals have been exemplified as role models to the participants in the study. This may have contributed to why Leonard did not respond with the RtB and why he often stated that the confederates were not mean to him, but later was reported to utilize the RtB when peers made bully statements to him. Future research could assess other possibilities for confederate selection to increase the likelihood that participants will perceive the confederates as bullies. Future research could also evaluate the effects of this intervention on the behavior of the perpetrators of bullying who are already present in the natural environment. Ross and Horner (2009) evaluated the frequency of bullying following their intervention during 10min increments. Future research could evaluate this procedure with the perpetrators of bullying already in the natural environment (instead of using confederates), over longer durations of time, such as entire days.

Not only were the interventions effective at teaching the RtB, but also the results of the social validity questionnaires suggest a high acceptability and effectiveness for the procedures by both participants and staff. Both staff and clients reported they would recommend the intervention to other clients at this site. All participants and confederates also reported that they felt using the RtB helps them to stay safe. This procedure is not costly to implement, nor does it require many materials or extensive training.

Additionally, there are several anecdotal accounts that support the effectiveness and acceptability of the intervention. For example, staff reported that Leonard, who struggled the 
most with this procedure, is using the RtB four to six times a day and is even reporting to staff when other residents bully each other. Sheldon, the participant who attended a separate ADT and work program, stated that he uses the RtB on his van to ADT and it has resulted in less bullying from others. Third, the main confederate who assisted with this study was very eager to help and became very excited when the participants showed improvement. In addition, while it was a concern that teaching the confederates to bully the participants during ISA may result in increased bullying by the confederates to other individuals, no reports or observations have been made of any bullying by these confederates following the study. Additionally, all three confederates reported that they have used the RtB themselves in bully situations that occurred at their workplaces after the training. One confederate reported that he used the RtB in a situation where a coworker attempted to physically aggress towards him outside the building; he went back inside and reported the incident to his supervisor. The other confederates also reported that they told their supervisors at work about the incidents immediately when they occurred. Two of the confederates reported these incidents to the clinical director at the study site via telephone call after the incidents where she was able to provide further support regarding the incidents. Some difficulties worth noting include: few confederate participants volunteered to complete ISA and IST and those that did volunteer were not available for weeks at a time on occasion which limited opportunities to view generalization across the bully confederates. Also, on some occasions, substantial time lapsed between trainings and assessments. BST and IST conducted with shorter time between trainings may result in participants engaging in more steps of the RtB. Additionally, IST involves the researchers assessing the participant, unknown to the participant. The setting these assessments took place in occasionally made it difficult to keep the researchers hidden. Also, three of the four participants lived in the same group home, which 
made ISA and IST difficult to conduct with the same confederate and researchers.

The findings of this study have several implications for future research. Future research could assess overall rates of bullying in the natural environment (physical and verbal aggression) before and after intervention. Future research could also evaluate these procedures in ISA when peers are present in the environment to assess whether participants would respond the same when they are in front of their friends who may encourage them to respond differently. Furthermore, a functional analysis of bullying behavior may be beneficial in selecting intervention options. In addition, longer training sessions with multiple staff present during training role-plays and peer trainings should be evaluated with this procedure.

In conclusion, this study is one of the few that teaches victims of bullying a way to respond by removing the hypothesized reinforcer (Ross \& Horner, 2009) and the first study known to the researchers that teaches these skills to adults with intellectual disabilities. 


\section{Tables and Figures}

Table 1

The responses of participants and confederates on the social validity questionnaire. $(N=6)$

\begin{tabular}{|c|c|c|c|c|c|}
\hline Question & $\begin{array}{l}\text { Do you think using } \\
\text { this assertive } \\
\text { response helps you } \\
\text { stay safe? }\end{array}$ & $\begin{array}{c}\text { Do you think your } \\
\text { friends would use } \\
\text { this? }\end{array}$ & $\begin{array}{l}\text { Would you say } \\
\text { this assertive } \\
\text { response in the } \\
\text { future? }\end{array}$ & $\begin{array}{c}\text { Do you think using } \\
\text { this strategy will } \\
\text { stop others from } \\
\text { bullying you? }\end{array}$ & $\begin{array}{l}\text { Have you used } \\
\text { this response } \\
\text { with anyone } \\
\text { who bullied } \\
\text { you since } \\
\text { training } \\
\text { occurred? }\end{array}$ \\
\hline Yes & 6 & 6 & 5 & 4 & 4 \\
\hline No & & & & 2 & 2 \\
\hline Maybe & & & 1 & & \\
\hline
\end{tabular}


Table 2

The responses of staff on the social validity questionnaire. $(N=4)$

\begin{tabular}{|c|c|c|c|}
\hline Question & $\begin{array}{l}\text { Would you recommend it } \\
\text { to other clients? }\end{array}$ & $\begin{array}{l}\text { Do you think this } \\
\text { training changed how } \\
\text { the participants respond } \\
\text { to bullying? }\end{array}$ & $\begin{array}{l}\text { Do you think using this } \\
\text { assertive response } \\
\text { resulted in less bully } \\
\text { interactions overall? }\end{array}$ \\
\hline Yes & 4 & 3 & 3 \\
\hline No & & & 1 \\
\hline Maybe & & 1 & \\
\hline
\end{tabular}




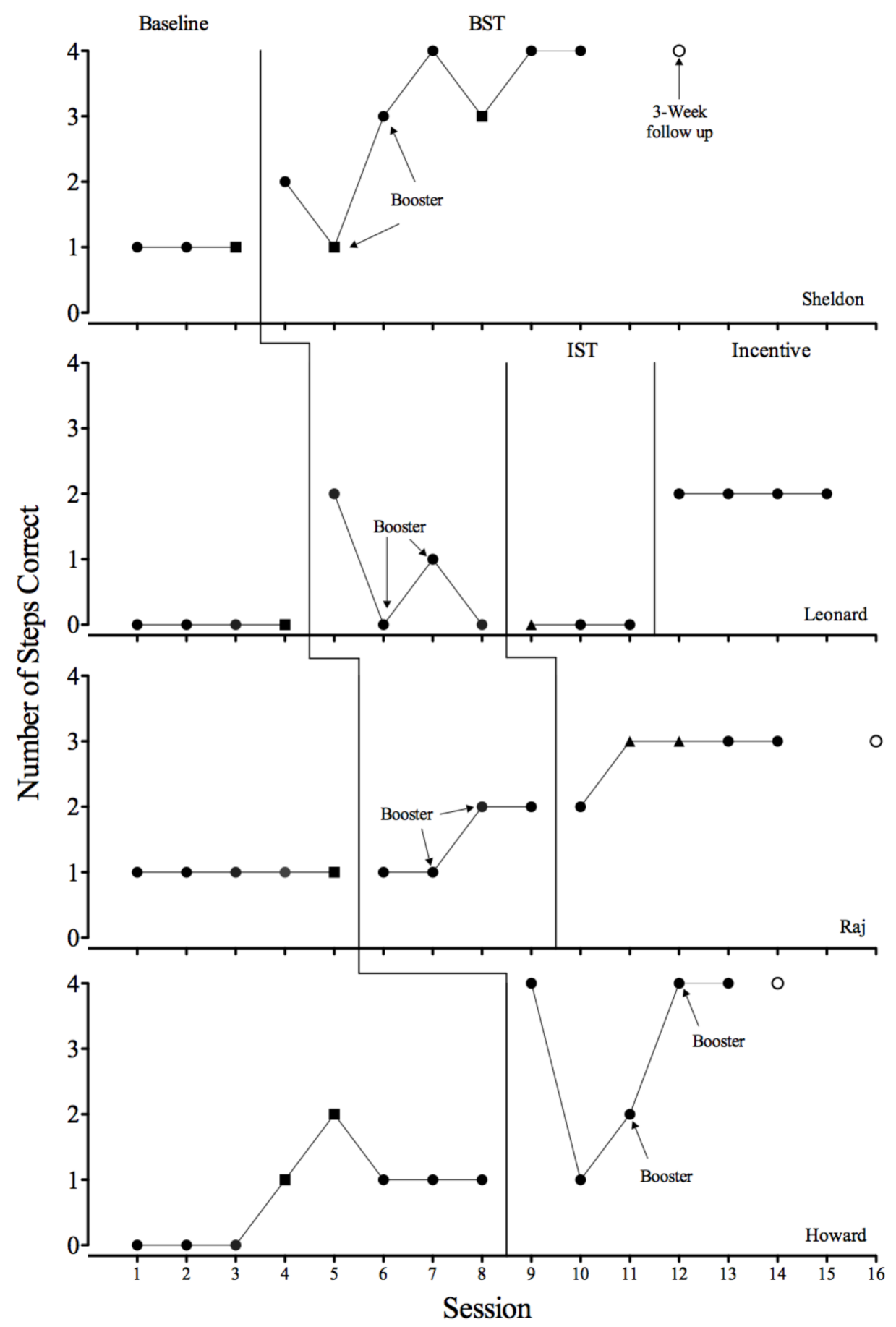

Figure 1. Rating-scale scores for participants across baseline, BST, IST, and incentive phases. The closed circles represent confederate 1 , the closed squares represent confederate 2 , and the closed triangles represent confederate 3. The open circles represent a 3-week follow up assessment. 


\section{References}

Bramston, P., Fogarty, G., \& Cummins, R. A. (1999). The nature of stressors reported by people with an intellectual disability. Journal of Applied Research in Intellectual Disabilities, 12, 1-10. doi:10.1111/j.1468-3148.1999.tb00046.x

Christensen, L. L., Fraynt, R. J., Neece, C. L., \& Baker, B. L. (2012). Bullying adolescents with intellectual disability. Journal of Mental Health Research in Intellectual Disabilities, 5(1), 49-65. doi:10.1080/19315864.2011.637660

Colvin, G., Tobin, T., Beard, K., Hagan, S., \& Sprague, J. (1998). The school bully: Assessing the problem developing interventions, and future research directions. Journal of Behavioral Education, 8(3), 293-319.

Craig, W., Pepler, D., \& Blais, J. (2007). Responding to bullying: What works? School Psychology International, 28(4), 465-477. doi:10.1177/0143034307084136

Egemo-Helm, K. R., Miltenberger, R. G., Knudson, P., Finstrom, N., Jostad, C., \& Johnson, B. (2007). Behavioral Interventions, 22, 99-119. doi: 10.1002/bin.234

Fried, S. E., \& Fried, P. (1996). Bullies \& victims: Helping your child survive the schoolyard battlefield. New York, New York: M. Evans and Co.

Garrity, C., Jens, K., Porter, W. W., Sager, N., \& Short-Camilli, C. (1997). Bully proofing your school: Creating a positive climate. Intervention in School and Clinic, 32(4), 235-243. doi:10.1177/105345129703200407 
Gatheridge, B. J., Miltenberger, R. G., Huneke, D. F., Satterlund, M. J., Mattern, A. R., Johnson, B. M., \& Flessner, C. A. (2004). Comparison of two programs to teach firearm injury prevention skills to 6- and 7- year-old children. Pediatrics, 114, 294-299.

Himle, M. B., Miltenberger, R. G., Flessner, C., \& Gatheridge, B. (2004). Teaching safety skills to children to prevent gun play. Journal of Applied Behavior Analysis, 37, 1-9.

McGrath, L., Jones, R. S., \& Hastings, R. P. (2010). Outcomes of anti-bullying intervention for adults with intellectual disabilities. Research in Developmental Disabilities, 31, 376-380. doi:10.1016/j.ridd.2009.10.006

Mencap. (1999). Living in Fear:The Need to Combat Bullying of People with a Learning Disability. Retrieved from https://www.mencap.org.uk/sites/default/files/documents/2009-10/Livinginfear.pdf

Miltenberger, R. G. (2008). Behavior modification: Principles and procedures. Belmont, CA: Thomson Wadsworth.

Miltenberger, R. G., Flessner, C., Gatheridge, B., Johnson, B., Satterlund, M., \& Egemo, K. (2004). Evaluation of behavioral skills training procedures to prevent gun play in children. Journal of Applied Behavior Analysis, 37, 513-516.

Miltenberger, R. G., Gatheridge, B. J., Satterlund, M., Egemo-Helm, K. R., Johnson, B. M., Jostad, C., \& Flessner, C. A. (2005). Teaching safety skills to prevent gun play: An evaluation of in situ training. Journal of Applied Behavior Analysis, 38, 395-398.

Miltenberger, R. G., Roberts, J. A., Ellingson, S., \& Galensky, T. (1999). Training and generalization of sexual abuse prevention skills for women with mental retardation. Journal of Applied Behavior Analysis, 32, 385-388. 
Reiter, S., \& Lapidot-Lefler, N. (2007). Bullying among special education students with intellectual disabilities: Differences in social adjustment and social skills. Intellectual and Developmental Disabilities, 3, 174-181. doi:10.1352/1934-9556(2007)45[174:BA

Ross, S. W., \& Horner, R. H. (2009). Bully prevention in positive behavior support. Journal of Applied Behavior Analysis, 42, 747-759. doi:10.1901/jaba.2009.42-747

Sanchez, S., \& Miltenberger, R. G. (2015). Evaluating the effectiveness of an abduction prevention program for young adults with intellectual disabilities. Child \& Family Behavior Therapy, 37(3), 197-207, DOI: 10.1080/07317107.2015.1071178

Travis, R. W., \& Sturmey, P. (2013). Using behavioral skills training to treat aggression in adults with mild intellectual disability in a forensic setting. Journal of Applied Research in Intellectual Disabilities, 26, 481-488. doi:10.1111/jar.12033

Yang, A., \& Salmivalli, C. (2015). Effectiveness of the KiVa antibullying programme on bully-victims, bullies and victims. Educational Research. 57 80-90. doi: $10.1080 / 00131881.2014 .983724$ 
Appendix A: Sample Data Collection Sheet

\begin{tabular}{|c|c|c|c|c|c|c|c|c|c|c|c|c|c|}
\hline Date & $\begin{array}{l}\text { Step 1: } \\
\text { Walk up } \\
\text { to } \\
\text { particip } \\
\text { ant }\end{array}$ & $\begin{array}{c}\text { Step 2: } \\
\text { say short } \\
\text { bully } \\
\text { statement }\end{array}$ & $\begin{array}{c}\text { Step 3: } \\
\text { walk } \\
\text { away at } 5 \\
\text { sec. or } \\
\text { after } \\
\text { participa } \\
\text { nt }\end{array}$ & $\begin{array}{l}\text { Step 4: Do } \\
\text { not say/do } \\
\text { anything } \\
\text { else other } \\
\text { than the } \\
\text { first } 3 \\
\text { steps }\end{array}$ & $\begin{array}{l}\text { Additional } \\
\text { notes }\end{array}$ & Score & $\begin{array}{c}\text { Step 1: } \\
\text { do not } \\
\text { retaliate }\end{array}$ & $\begin{array}{c}\text { Step 2: } \\
\text { comment } \\
\text { of } \\
\text { disappro } \\
\text { val }\end{array}$ & $\begin{array}{l}\text { Step 3: } \\
\text { walk } \\
\text { away } \\
\text { before } \\
\text { conf. }\end{array}$ & $\begin{array}{c}\text { Step 4: } \\
\text { tell a } \\
\text { staff } \\
\text { member }\end{array}$ & $\begin{array}{c}\text { Additional } \\
\text { notes }\end{array}$ & $\begin{array}{c}\text { State } \\
\text { ment } \\
\#\end{array}$ & Score \\
\hline $10 / 1 / 14$ & $\checkmark$ & $\checkmark$ & $\checkmark$ & $\checkmark$ & & 4 & $\checkmark$ & $\checkmark$ & $\checkmark$ & $\checkmark$ & & 10 & 4 \\
\hline $10 / 2 / 14$ & $\checkmark$ & $\checkmark$ & $x$ & $x$ & $\begin{array}{l}\text { Joined in a } \\
\text { game of } \\
\text { basketball } \\
\text { with } \\
\text { participant } \\
\text { instead of } \\
\text { walking } \\
\text { away }\end{array}$ & 2 & $\checkmark$ & $\checkmark$ & $x$ & $x$ & $\begin{array}{l}\text { Invited the } \\
\text { confederate } \\
\text { to play } \\
\text { basketball }\end{array}$ & 2 & 2 \\
\hline $10 / 3 / 14$ & $\checkmark$ & $\checkmark$ & $\checkmark$ & $\checkmark$ & & 4 & $\checkmark$ & $\checkmark$ & $\checkmark$ & $x$ & $\begin{array}{c}\text { Did not tell } \\
\text { staff, staff } \\
\text { observed it } \\
\text { happen }\end{array}$ & 7 & 3 \\
\hline & & & & & & & & & & & & & \\
\hline
\end{tabular}




\section{Appendix B: Sample Bully Statements}

Threats of Personal Harm

- "I'm going to rip your head off"

- "I'm going to bury you alive"

- "I'm going to beat you up"

- "I really feel like punching you right now"

Threats of Loss of Privileges/Property

- "I'm going to make you get your level reduced"

- "I'm going to get you in trouble with staff and make you lose your (behavior) contract"

- "Staff are moving you to another house because you have been bad"

- "I'm going to take that money when you fall asleep"

- "I'm not inviting you to my birthday party"

- Taking an item (chicken, cookie, book, lunch box) and saying "it's mine now!"

Personal Defamations/Name Calling

- "You're just a fatso"

- "You're so fat and ugly"

- "That's a stupid haircut, did you cut it yourself?"

- “They aren't your friends, you don't have any friends

Obscenities (including swearing or rude gestures)

- "Fuck you, bitch"

- "How do you like that, motherfucker"

- Giving the middle finger 


\title{
Appendix C: IRB Approval
}

\author{
JOP \\ RESEARCH INTEGRITY AND COMPLIANCE \\ Institutional Review Boards, FWA No. 00001669 \\ 12901 Bruce B. Downs Blvd., MDC035 • Tampa, FL $33612-4799$ \\ UNIVERSITY OF \\ SOUTH FLORIDA \\ $3 / 19 / 2015$ \\ Rebecca Stannis, B.S. \\ ABA-Applied Behavior Analysis \\ 13301 Bruce B. Downs Blvd \\ Tampa FL 33612

\section{RE: Full Board Approval for Initial Review} \\ IRB\#: Pro00020152 \\ Title: Response to Bullying (RtB): Behavioral Skills and In Situ Training for Individuals \\ Diagnosed with Intellectual Disabilities \\ Study Approval Period: 2/20/2015 to 8/20/2015 \\ Dear Ms. Stannis: \\ On 2/20/2015, the Institutional Review Board (IRB) reviewed and APPROVED the above \\ application and all documents outlined below. \\ The IRB has approved this study for one participant. Once that participant has completed \\ the study intervention please submit a Reportable Event as "Other" to the IRB to \\ summarize research activities. \\ Approved Item(s): \\ Protocol Document(s): \\ USF IRB protocol stannis - no track changes.docx \\ Consent/Assent Document(s)*: \\ Informed Consent confederate revised.docx.pdf \\ Informed Consent participant revised.docx.pdf \\ *Please use only the official IRB stamped informed consent/assent document(s) found under the \\ "Attachments" tab. Please note, these consent/assent document(s) are only valid during the \\ approval period indicated at the top of the form(s). \\ As the principal investigator of this study, it is your responsibility to conduct this study in \\ accordance with IRB policies and procedures and as approved by the IRB. Any changes to the
}


approved research must be submitted to the IRB for review and approval by an amendment.

We appreciate your dedication to the ethical conduct of human subject research at the University of South Florida and your continued commitment to human research protections. If you have any questions regarding this matter, please call 813-974-5638.

Sincerely,

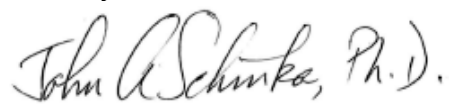

John Schinka, Ph.D., Chairperson

USF Institutional Review Board 


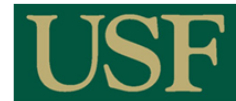

UNIVERSITY OF

SOUTH FLORIDA

$7 / 20 / 2015$

Rebecca Stannis, B.S.

ABA-Applied Behavior Analysis

13301 Bruce B Downs Blvd.

MHC 2113A

Tampa, FL 33612

RE: Full Board Approval for Continuing Review

IRB\#: CR1_Pro00020152

Title: Response to Bullying (RtB): Behavioral Skills and In Situ Training for Individuals Diagnosed with Intellectual Disabilities

Study Approval Period: 8/20/2015 to 8/20/2016

Dear Ms. Stannis:

On 7/17/2015, the Institutional Review Board (IRB) reviewed and APPROVED the above application and all documents contained within, including those outlined below.

\section{Approved Item(s):}

Protocol Document(s):

USF IRB protocol stannis - no track changes.docx

As the principal investigator of this study, it is your responsibility to conduct this study in accordance with USF HRPP policies and procedures and as approved by the USF IRB. Any changes to the approved research must be submitted to the IRB for review and approval via an amendment. Additionally, all unanticipated problems must be reported to the USF IRB within five (5) calendar days.

We appreciate your dedication to the ethical conduct of human subject research at the University of South Florida and your continued commitment to human research protections. If you have any questions regarding this matter, please call 813-974-5638.

Sincerely,

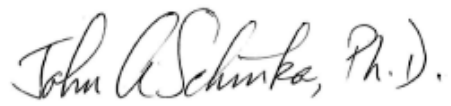

John Schinka, Ph.D., Chairperson

USF Institutional Review Board
Institutional Review Boards, FWA No. 00001669

(813) 974.5638 - FAX (813) 974.709 